This item was submitted to Loughborough's Research Repository by the author.

Items in Figshare are protected by copyright, with all rights reserved, unless otherwise indicated.

\title{
Experimental study on stoichiometric laminar flame velocities and Markstein lengths of methane and PRF95 dual fuels
}

PLEASE CITE THE PUBLISHED VERSION

http://dx.doi.org/10.1016/j.fuel.2016.06.047

\section{PUBLISHER}

(C) Elsevier

VERSION

AM (Accepted Manuscript)

\section{PUBLISHER STATEMENT}

This work is made available according to the conditions of the Creative Commons Attribution-NonCommercialNoDerivatives 4.0 International (CC BY-NC-ND 4.0) licence. Full details of this licence are available at: https://creativecommons.org/licenses/by-nc-nd/4.0/

\section{LICENCE}

CC BY-NC-ND 4.0

\section{REPOSITORY RECORD}

Petrakides, Sotiris, Rui Chen, Dongzhi Gao, and Haiqiao Wei. 2016. "Experimental Study on Stoichiometric Laminar Flame Velocities and Markstein Lengths of Methane and PRF95 Dual Fuels”. figshare. https://hdl.handle.net/2134/21831. 


\title{
1 Experimental Study on Stoichiometric Laminar Flame
}

\section{Velocities and Markstein Lengths of Methane and PRF95}

\section{Dual Fuels}

\author{
4 Sotiris Petrakides ${ }^{a}$, Rui Chen ${ }^{a,{ }^{*}}$, Dongzhi Gao ${ }^{b}$, Haiqiao Wei ${ }^{b}$ \\ 5 a Department of Aeronautical and Automotive Engineering, Loughborough University, LE11 3TU, United \\ 6 Kingdom \\ 7 b Sate Key Laboratory of Engines (SKLE), Tianjin University, Tianjin 300072, China \\ 8 * Corresponding author. \\ 9 E-mail address: r.chen@lboro.ac.uk
}

\section{Abstract}

12 Natural gas is one of the most promising alternative fuels. The main constituent of natural gas is methane. The 13 slow burning velocity of methane poses significant challenges for its utilization in future energy efficient combustion applications. Methane-gasoline dual fuelling has the potential to improve methane's combustion. The fundamental combustion characteristics of a methane-gasoline Dual Fuel (DF) blend needs further investigation. In the current experimental study, the relationship between laminar flame velocity and Markstein length, with the ratio of gas to liquid in a DF blend has been investigated using spherical flames in a constant volume combustion vessel. A binary blend of primary reference fuels (PRF95) was used as the liquid fuel. Methane was added to PRF95 in three different energy ratios $25 \%, 50 \%$ and $75 \%$. Values of the stoichiometric laminar flame velocities and Markstein lengths are measured at pressures of 2.5, 5, 10 Bar and a temperature of $373 \mathrm{~K}$. It has been found that with a $25 \%$ increase in the DF ratio, the Markstein length is reduced by $15 \%, 21 \%, 32 \%$ at a pressure of 2.5 , 5 and 10 Bar respectively whereas at the same pressures the laminar flame velocity is reduced by $2 \%, 3 \%$ and $5 \%$. The flame evolution at the early stages of combustion is found to be faster with an increase in the DF ratio, and gradually as the flame develops it becomes slower.

27 Alternative fuels have a central contribution towards compliance with future emission legislations. Attributed mainly to its low carbon content and abundance reserves, methane can be classified as one of the most 
promising alternative fuels. Historically, the slow burning velocity of methane has been a major concern for its

30 utilisation in real energy efficient combustion applications. As emphasized in literature on experimental studies in

31 SI engines [1,2], the addition of gasoline to methane (Methane-gasoline dual fuelling) has the potential to improve methane's combustion, leading to an enhanced initial establishment of burning velocity even compared to that of gasoline.

34 Practical combustion phenomena, including burning velocity in SI engines, are governed by the fundamental 35 laminar flame velocity $\left(\mathrm{S}_{\mathrm{u}}{ }^{0}\right)$ of the fuel-oxidizer mixture. Since all realistic flames are curved and/or travel through 36 a strained flow field, another fundamental mixture parameter known as the Markstein length ( $\left.L_{b}\right)$, which quantifies 37 the response of the flame velocity to stretch rate, is also necessary to characterise flame behaviour more completely [3].

Substantial efforts have been devoted for improving the understanding on methane as well as gasoline combustion. Typical refinery gasoline consists of hundreds of hydrocarbons. Iso-octane as well as binary blends

41 of primary reference fuels have been widely adopted as convenient gasoline surrogates. Studies reporting values 42 of laminar flame velocities at elevated pressures have been conducted for gasoline [4,5] and its surrogates

$43[5,6,7,8]$ as well as methane $[9,10,11]$. In all the above studies the reported laminar flame velocity of methane is 44 consistently lower compared to that of gasoline and its surrogates when tested at similar conditions. The stretch sensitivity of iso-octane and methane air mixtures characterised by the Markstein length has been also reported in literature $[6,9,10]$. A part of the study of Gu et al. [9] compared the Markstein length of iso-octane and methane air mixtures at stoichiometric and lean conditions. As emphasized, these two fuels responded to flame stretch differently, both with respect to equivalence ratio as well as pressure.

As stated by Brequigny et al. [12], the flame stretch sensitivity observed in the laminar regime directly impacts the combustion process in an SI engine. The study of Petrakides et al. [13] quantifies the response of mass burning rate with methane addition to PRF95 in a constant volume combustion vessel and natural gas addition to gasoline in an SI engine. A comparison of burning rates between the two experimental environments reveal very

53 similar qualitative trends supporting the comments of Brequigny et al. that phenomena of flame velocity and 54 stretch interactions observed in the laminar regime are still applicable in the engine environment. properties, the so-called Lewis number effect [14-16]. The Lewis number is defined as the ratio of thermal to

57 mass diffusivity of the combustible mixture. It has been reported in literature that the phasing of 5\%, 10\% and $5850 \%$ mass fraction burned in an SI engine is linearly linked to the Lewis number and therefore to the Markstein 59 Length $[12,17]$ of the fuel-air mixture. It has been also reported by the same research group that the burning rate of high stretch sensitive fuels such as iso-octane, slow down when high levels of flame stretch is induced on the 
61 flame through an increase of engine speed [18]. In the particular studies [12,17,18], the considered fuel-air

62 mixtures in the SI engine were examined at different equivalence ratios to present similar laminar flame velocities

63 at ignition timing, and therefore allow for the effect of the fuel's stretch sensitivity on the burning velocity to be

64 investigated. Methane being the least sensitive fuel has shown the fastest combustion, in contrast to iso-octane

65 being the most stretch sensitive fuel shown the slowest. The interactions of burning velocity with flame stretch in

66 SI engines have been also investigated by the study of Aleifraris et al [19]. The study reports that fuels with low

67 stretch sensitivity have the tendency to produce faster burning velocities in the early stages of combustion.

68 A comprehensive understanding of these two fundamental mixture parameters, laminar flame velocity and

69 Markstein length, is essential for the development of energy efficient combustion applications. The laminar flame 70 velocity and Markstein length of a methane-gasoline dual fuel blend needs further investigation. It is the aim of

71 this study to experimentally investigate the relationship between laminar flame velocity and Markstein length, with

72 the ratio of gas to liquid in a dual fuel blend. In the current experimental work a binary blend of primary reference

73 fuels commonly known as PRF95 (95\%volliq of iso-octane and 5\%vol liq $\mathrm{n}$-heptane) was used as the liquid fuel.

74 Methane was used as the gaseous fuel. Values of stoichiometric laminar flame velocities and Markstein lengths

75 are measured at pressures of 2.5, 5, 10 Bar and a temperature of $373 \mathrm{~K}$.

2) Experimental Technique

\section{1) System Integration}

79 A 100mm inner diameter cylindrical combustion vessel with a volume of 2.2L was employed for the experimental 80 study. The experimental setup is illustrated in Figure 1. Optical access was possible through two opposing

$8180 \mathrm{~mm}$ circular windows attached near the side of the vessel. The entire vessel was preheated uniformly by a set of electrical heating elements totaling $3.2-\mathrm{kW}$. One of the heaters was fully inserted inside the vessel to induce a transient temperature difference only during the filling process. The temperature difference evoked natural convection to stir the mixture enhancing the mixing of fuel and air. Similar technique has been used by Jerzembeck et al. [5]. The interior air temperature was controlled within $3 \mathrm{~K}$ using a closed-loop feedback controller set to $373 \mathrm{~K}$. The temperature could also be observed manually from a second temperature sensor mounted on the top of the vessel. The pressure rise during the combustion process was obtained using a Kistler 6113B pressure transducer. The mixture was ignited using a slightly modified standard ignition plug with extended electrodes of $1.35 \mathrm{~mm}$ in diameter. The ignition system generated a spark with duration of $0.7 \mathrm{~ms}$. For safety reasons, a $6 \mathrm{MPa}$ pressure release valve was installed on the combustion vessel. 


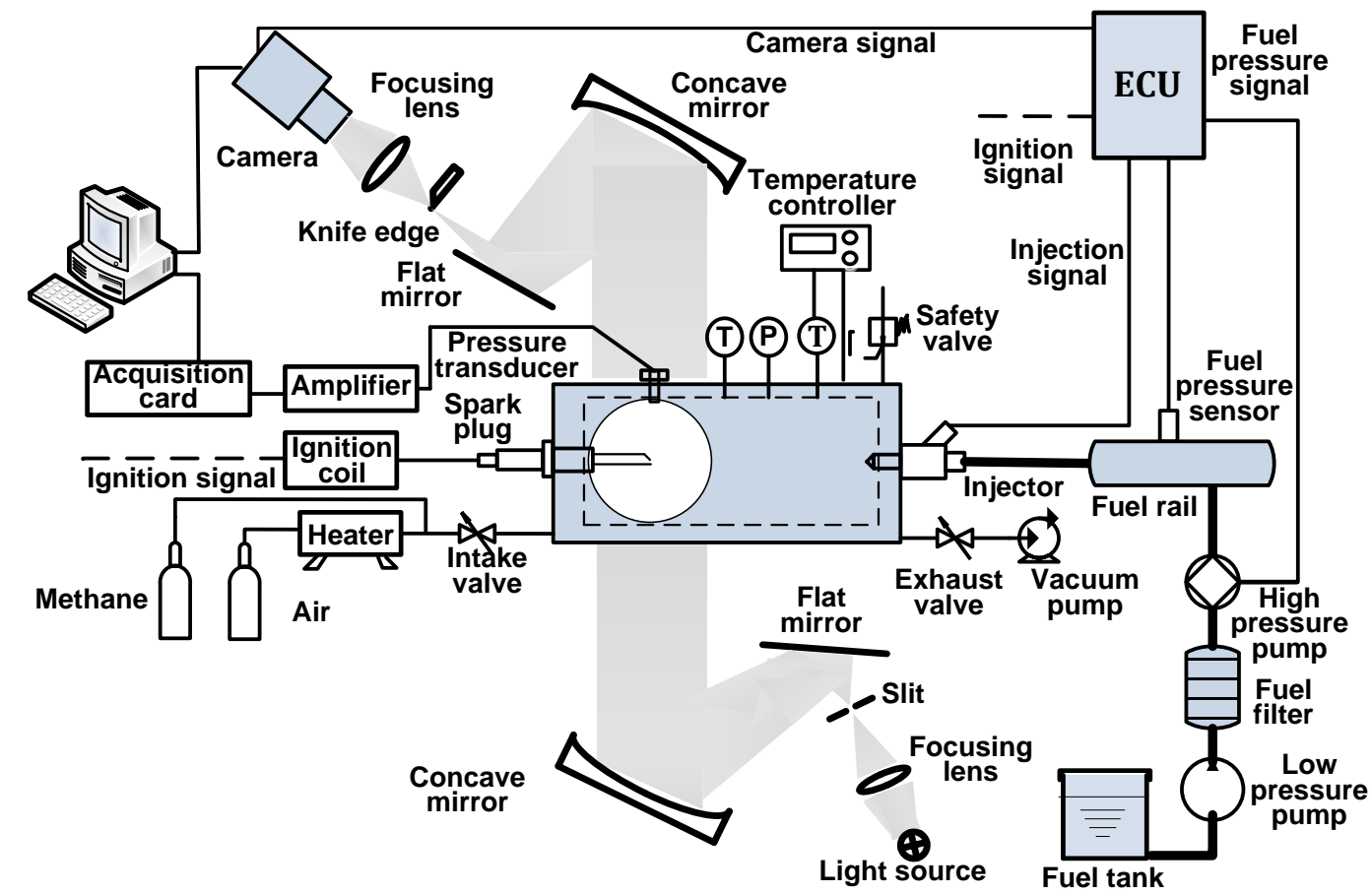

Figure 1 Schematic diagram of the experimental setup

93 The flame progress recorded at 6000 frames per second with a resolution of $512 \times 512$ pixels by high speed

94 Schlieren photography arranged in a Z configuration. A $245 \mathrm{~W}$ halogen lamp was used as the light source. The

95 light was focused onto a slit using a focusing lens in order to generate the spotlight for the Schlieren technique.

96 Passing through a group of mirrors, the light path was then cut by a knife-edge which is essential for the

97 Schlieren method [4]. Two different high speed cameras have been used for the current experimental work. A

98 Photron Fastcam SA5 was used for the experimental work at a pressure of 5 Bar, instead of a Photron Fastcam

99 SA-X2 that was used at 2.5 and 10 Bar. The high speed cameras were synchronized with the spark timing and

100 the interior pressure rise recording.

101

\section{2) Dual Fuel Mixture Preparation}

102 As the liquid fuel, PRF95 (95\%volliq iso-octane and 5\%volliq n-heptane) was used. High purity (99.9\%) methane

103 was used as the gaseous fuel. The dual fuel blends consist of methane and PRF95 in three different energy

104 ratios $(25 \%, 50 \%, 75 \%)$. A blend with 25\% of its energy contributing from methane as defined in Eq. 1 was

105 labelled as DF25, with 50\% DF50, and for 75\% DF75.

$D F_{\text {Ratio }}=\frac{M_{C H_{4}} \times L H V_{C H_{4}}}{M_{P R F 95} \times L H V_{P R F 95}+M_{C H_{4}} \times L H V_{C H_{4}}}$

106 The air to fuel ratio was set to stoichiometric throughout the study for all investigated conditions. The

107 stoichiometric air to fuel ratio was calculated using the method of chemical balance and assuming products of 
108 complete combustion. High purity technical air was used with an oxidizer concentration [O2/(O2+N2)] of $0.2 \pm$ 1090.01.

110 In every experimental condition, the air to fuel ratio was prepared inside the vessel using the partial pressure

111 method. Initially the vessel was heated up to the desired temperature (373 K). Whilst the heater mounted inside

112 the vessel was turned on, the liquid fuel was injected into the combustion vessel using a multi-hole gasoline

113 direct injector with an injection pressure of $12 \mathrm{MPa}$. The targeted fuel mass was supplied inside the combustion

114 vessel by individual injections using pre-calibrated data. The pre-calibration process involves the determination of

115 the mass of liquid per single injection. After the injections were completed, two minutes were given to allow for

116 the complete evaporation of the liquid fuel. Considering the correct increase in pressure inside the vessel caused

117 by the evaporation of the liquid fuel compared to the thermodynamic ideal-gas law calculations, methane and

118 then air fed in slowly using a fine needle valve and a pressure transducer to control the filling process. The

119 technical air was heated by an external heater before flowing into the combustion vessel to better approximate an

120 isothermal filling process. After the filling process was completed the interior heater was turned off, and three

121 minutes of quiescence were given to minimize any flow structures and/or temperature stratifications inside the

122 vessel. The quiescence time also promotes the homogeneous mixing of fuel and air.

123 For each test condition, the described experimental procedure that allowed the evaluation of the fundamental

124 laminar flame velocity as well as burned gas Markstein length was carried out at a minimum of three times. The

125 average values are reported as well as error bars evaluated based on standard error. 
127 A common approach of measuring burning velocity and Markstein length in a combustion vessel has been the

128 constant pressure outwardly propagating spherical flame method [4-10]. The method is suitable for extrapolation

129 of measured stretched burning velocities to their fundamental non-stretched values and the associate Markstein

130 lengths due to the well-defined stretch rates of an outwardly spherical flame. The constant pressure outwardly

131 propagating spherical flame method in combination with the relation given by Strehlow and Savage [20] have

132 been used by most of the studies in literature $[3,4,5,7,8]$. The relation of Strehlow and Savage derived on the

133 assumption that the burned gas is coming to rest after crossing an infinitesimally thin flame such as :

$S_{u}^{0}=\frac{1}{\sigma} S_{b}^{0}$

134 Where $\mathrm{S}_{\mathrm{u}}{ }^{0}$ is the fundamental laminar flame velocity, $\mathrm{S}_{\mathrm{b}}{ }^{0}$ is the unstretched burning velocity, and $\sigma$ is the thermal expansion factor defined as the ratio of unburned to burned gas density.

136 The fundamental laminar flame velocity is defined as the velocity at which a one-dimensional planar, adiabatic

137 flame travels through a quiescent unburned gas mixture. The flame stretch rate can collectively describe the 138 various influences due to flow nonuniformity, flame curvature, and flow/flame unsteadiness on the surface of an 139 outwardly propagating spherical flame [21]. It is defined as:

$$
\alpha=\frac{2}{R_{f}} S_{b}
$$

140 Where $R_{f}$ is the instantaneous flame radius, and $S_{b}$ the stretched burning velocity corresponding to the flame radii 141 over time, measured by an in house flame processing code.

142 The method developed by Markstein [22] relates the stretched burning velocity with its corresponding stretch

143 rate. Through a linear extrapolation of $S_{b}$ back to zero stretch using relation 4 , the value of the unstretched

144 burning velocity $\left(\mathrm{S}_{\mathrm{b}}{ }^{0}\right)$ and the associate burned gas Markstein length $\left(\mathrm{L}_{b}\right)$ can be obtained.

$S_{b}^{0}=S_{b}+L_{b} \alpha$

145 For the Markstein theory to be satisfied exactly, it requires an unwrinkled, spherical, infinitesimally thin, weakly

146 stretched, adiabatic, quasi-steady flame with a constant expansion factor in a zero gravity, unconfined

147 environment [3]. These assumptions are not satisfied in practical applications, even in well-controlled

148 experiments.

149 The validity of the linear relation starts to be questionable when the Lewis number of a mixture significantly 150 deviates from unity. As reported by Kelley and Law [23], a nonlinear extrapolation between stretched burning 
151 velocity and stretch rate should be used for mixtures with Lewis numbers appreciably different from unity.

152 According to Halter et al. [24], the use of a nonlinear methodology is only required when the burned gas

153 Markstein length $\left(L_{b}\right)$ reaches or surpasses the unity value (in $\mathrm{mm}$ ). As will be illustrated in section 3.3 the

154 maximum value of $L_{b}$ measured in the current experimental study corresponds to $0.67 \mathrm{~mm}$. Following the

155 correlation derived by Halter et al. [24] for evaluating the relative percentage difference between linear and not

156 linear extrapolation methodology, the maximum difference in the current experimental study is lower than $1.3 \%$.

157 Therefore, it was concluded that in the current study a linear extrapolation methodology can still be used with

158 confidence.

159 Despite its limitations, the extrapolation of a spherical outwardly propagating flame to its zero stretch using the

160 Markstein method is widely accepted and used in literature [3-10]. This method has been applied in the present

161 study in order to allow a comparison of the measured values of $S_{u}{ }^{0}$ and $L_{b}$ with the existing related literature

162 information.

163 The required expansion factors have been computed using the model for a freely propagating flame in the

164 Cantera software package [25]. The numerical model was integrated with the reduced kinetic scheme of 165 Jurzemberck et all [5].

\section{4) Non-symmetrical Flame Restriction}

167 In the present experimental work, the use of a cylindrical combustion vessel instead of a spherical one imposes 168 non-symmetrical confinement on the outwardly flame evolution. According to Burke et al. [3], at flame radii ( $\left.R_{f}\right)$

169 larger than $30 \%$ of the vessel's radius $\left(R_{w}\right)$, the cylindrical vessel geometry excessively disrupts the induced flow

170 field from the unconfined case, causing the motion of burned gases within the burned zone. As a result,

171 significant departures can be experienced from the commonly employed spherical flame theory described in the 172 previous section.

173 To help the reader visualize the mentioned phenomena, a symbolic illustration is presented in Figure 2 . The

174 figure presents indicative flame surface contours as experienced during the current experimental work (solid

175 lines), in comparison to artificially symbolic circular contours that would correspond to an unconfined flame

176 evolution (dotted lines). At the early stages (i.e a,b), the burned gas is motionless and the flame shape remains

177 similar to that of the unconfined case. However, in contrast to the unconfined case, as the flame develops (i.e c-

$178 \mathrm{~d}-\mathrm{e})$, the burned gas deviates from its motionless state causing a non-similar flame propagation velocity along the

$179 \mathrm{X}$ and $\mathrm{Y}$ direction. Following the work of Burke et al. [3], flames were analyzed up to a maximum radius of $15 \mathrm{~mm}$

$180\left(R_{f} / R_{W}=0.3\right)$ to avoid any excessive motion of the burned gas that will cause departures from the applied flame

181 theory. 
183 to be addressed. An increase in pressure will reduce the flame velocity. As proposed in literature, the direct

184 pressure effect on the flame velocity can be reasonably neglected when the ratio of burned gas volume to the

185 vessel volume is less than 0.125 [3]. Within the present experimental work, at a maximum flame radius of $15 \mathrm{~mm}$,

186 the ratio of burned gas volume to the vessel's volume is considerably lower (0.00642) than the limiting value, due

187 to the large volume of the vessel. Therefore, the effects on the flame velocity from an increase in pressure were

188 neglected.

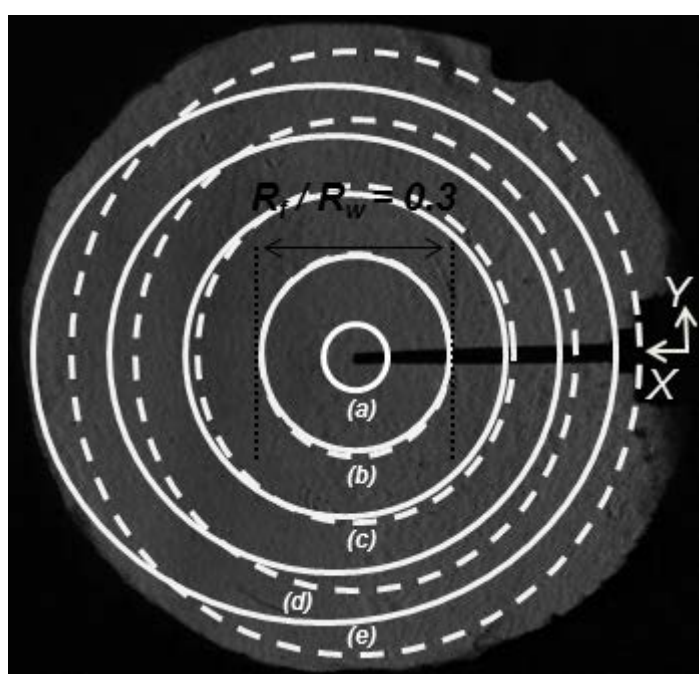

Figure 2. Symbolic illustration of flame surface contours for an unconfined (dotted lines) and cylindrically confined 191 (solid lines) flame propagation process.

\section{5) Image Processing and Radius Definition}

193 The flame surface was tracked with an in-house image processing code specifically developed for the current

194 experimental setup to track flame front radii over time. Despite not being the same as the cold flame radius [26],

195 the Schlieren image radius is commonly used in literature for flame velocity calculations $[4,5,8]$. The chronological

196 change in flame radius allows for the calculation of the stretched burning velocity.

197 The developed technique for measuring the chronological flame radius is based on the geometrical fact that a

198 circle can be calculated knowing at least three points on its periphery. The technique is illustrated in Figure 3 . For

199 all the experimental conditions, the technique was consistently applied from the fourth frame following the

200 initiation of spark where the flame could be clearly observed for all test conditions. In order to avoid the effects

201 from the electrodes, the left part of the flame's periphery is used for the analysis. The white dots represent the

202 points identified by the edge detection technique on the periphery of the flame, with points $\mathrm{A}$ and $\mathrm{C}$

203 corresponding to the upper and lower boundaries. For each particular image, points A and C are taken as the two

204 out of three needed for the calculation of a circle. Starting from point A and moving along the flame's periphery

205 towards $C$, each single point detected is used as the additional one needed for the calculation of a circle. All of 


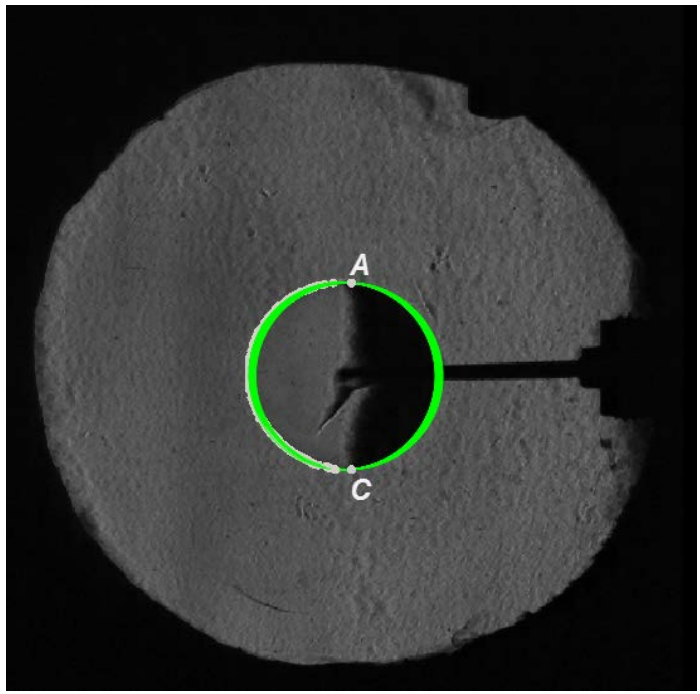

\section{3) Results - Discussion}

\section{1) Flame Morphology and Evolution}

\subsection{1) Flame Morphology}

216 A set of raw flame images of three different Dual Fuel (DF) ratios at a pressure of 5 Bar is presented in Figure 4.

217 A DF ratio of $0 \%$ corresponds to the pure liquid fuel (PRF95) whereas $100 \%$ corresponds to the gaseous fuel

$218\left(\mathrm{CH}_{4}\right)$.The time elapsed from the point of spark is shown. The presentation is limited at $7.93 \mathrm{~ms}$ as the DF 50

219 flame had reached the maximum allowed radius at that time. There are no signs of flame wrinkling or any

220 indication of cellular structures up to the maximum radius of analysis. Minor cracking can be observed on the

221 flame surface due to spark perturbation for all fuels. The shape of the flames appears smooth and therefore

222 stable independently of the fuel. As far as flame morphology is concerned, flames at a pressure of 2.5 Bar

223 shown consisted behaviour as in 5 Bar.

224 Another set of raw images, this time at a pressure of 10 Bar is presented in Figure 5. The morphology of the

225 flames at a randomly selected radius of about $10 \mathrm{~mm}$ can be observed for all the DF ratios. Flame stability at 10 
226 Bar appears to be affected by the DF ratio. As can be clearly observed from Figure 5, the wrinkling on the flame

227 surface is increased by moving from pure liquid (PRF95) having the largest Markstein Length, to pure gas (CH4)

228 having the lowest. This is in contrast to the observations of flame stability at 5 Bar. As reported in literature,

229 mixtures with low Markstein lengths have an increased propensity to instabilities [6 11 14]. Similar behaviour has 230 been observed in the current study. The same conclusions can be drawn if a different radius is selected as a

231 point of reference for the comparison of flame morphology of all test fuels.

232

233

234

235

236

237

238

239

240

241

242

243

244

245

246

247

248

249 
DF ratio (\%)

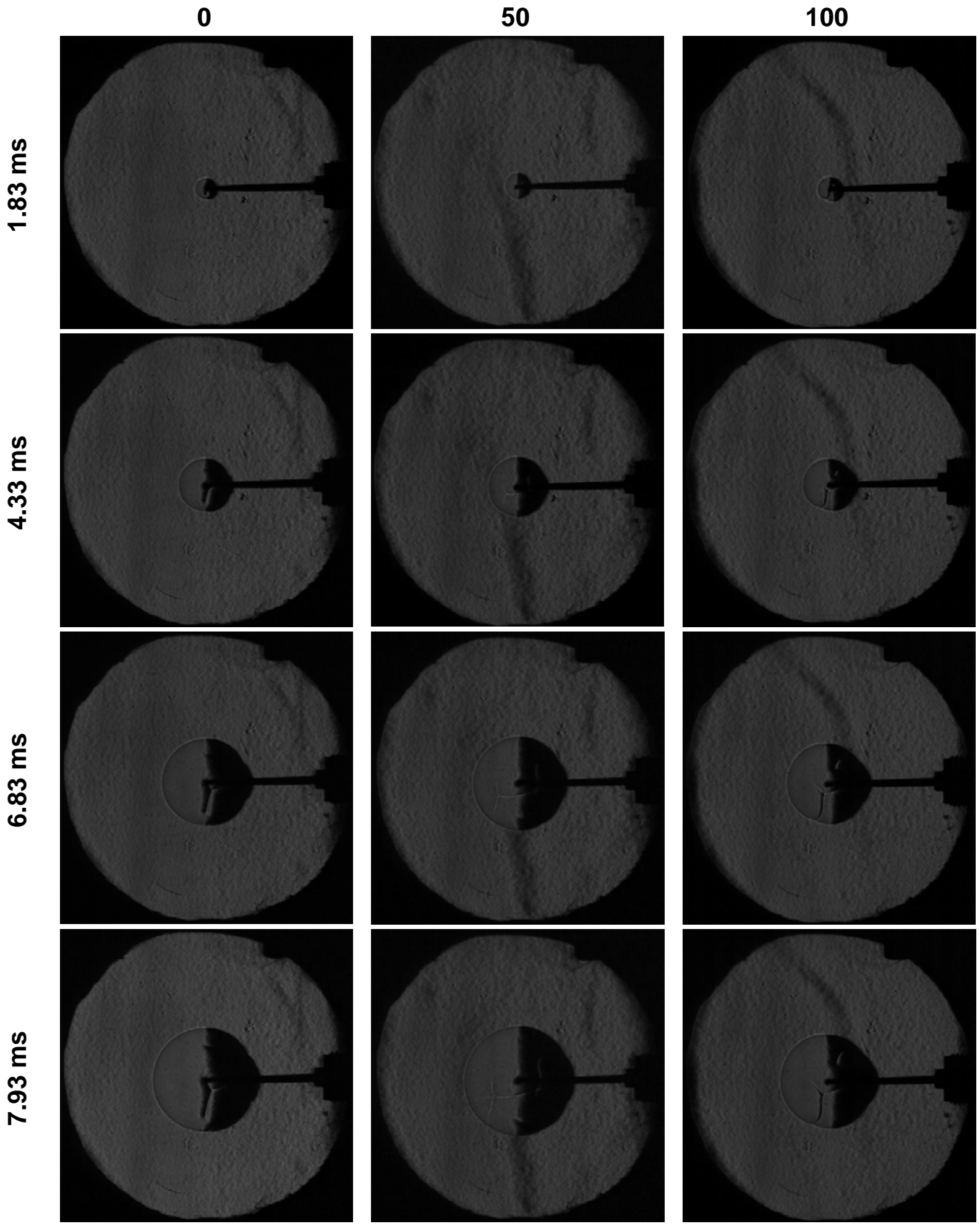

251 Figure 4. Chronological Schlieren images for three selected fuel-air mixtures. Pinitial $=$ 5Bar

252 For all fuels, wrinkles are triggered by the spark and remain similar in morphology as the flame expands. As

253 proposed by Rozenchan et al. [10] and supported by L.Qiao et al. [27] at the absence of cell cracking to smaller 
254 scales (cellularity) the linear relationship between velocity and stretch still holds. Even though the Markstein

255 theory can still be applied, the uncertainty in applying the theory is increased as the value of Markstein Length is 256 decreased.

\section{DF ratio (\%)}

0

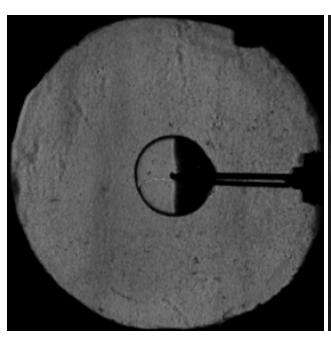

25

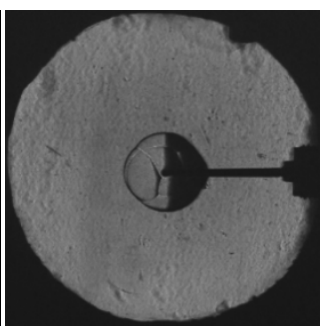

50

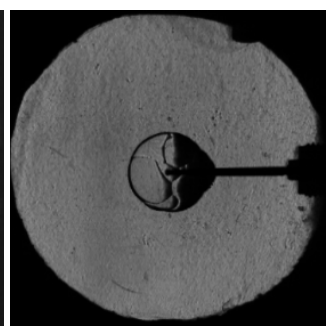

75

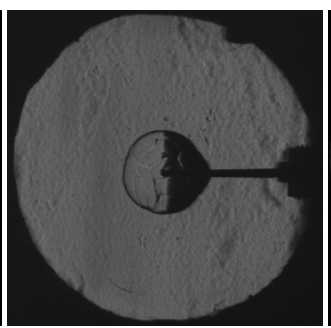

100

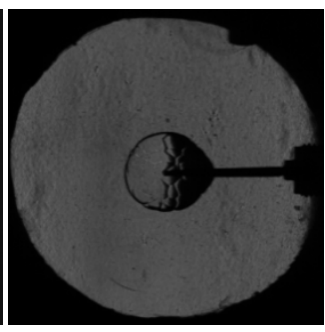

Figure 5. Schlieren flame images of all DF ratios at 10 Bar. Targeted radius : $10 \mathrm{~mm}$

258 At a pressure of 10 Bar, the burning velocity of DF75 resulted to be considerably higher compared to the rest of

259 the fuels. The response was consistent for all of its repeats. The higher burning velocity of DF75 is thought to be

260 caused by phenomena of flame instability. The effects of developed instability on the flame evolution are out of

261 the scope of this study.

\subsection{2) Flame Evolution}

263 The evolution of a stable flame is governed by the laminar flame velocity of a fuel-oxidizer mixture, and the

264 sensitivity of that flame to stretch characterised by the Markstein length. At a pressure of 5 Bar, the average radii

265 calculated from the different repeats of each fuel are presented in the upper plot of Figure 6. For each fuel, due to

266 the slightly different burning velocities at respective repeats, the average radius has been calculated only up to

267 the time where a minimum of three radii exist (one for each repeat). The presented times are consistent with

268 those of Figure 4 to allow for the visualization of flame evolution of the three selected fuels $\mathrm{CH}_{4}, \mathrm{DF}_{50}$ and

269 PRF95. At respective time steps up to $6.83 \mathrm{~ms}$, the percentage difference of the flame's radius of each fuel in

270 comparison to that of the pure liquid fuel (PRF95) has been calculated and presented in the lower plot of Figure

271 6. The change in flame's radius among the different DFs can be clearly observed at each time step. 

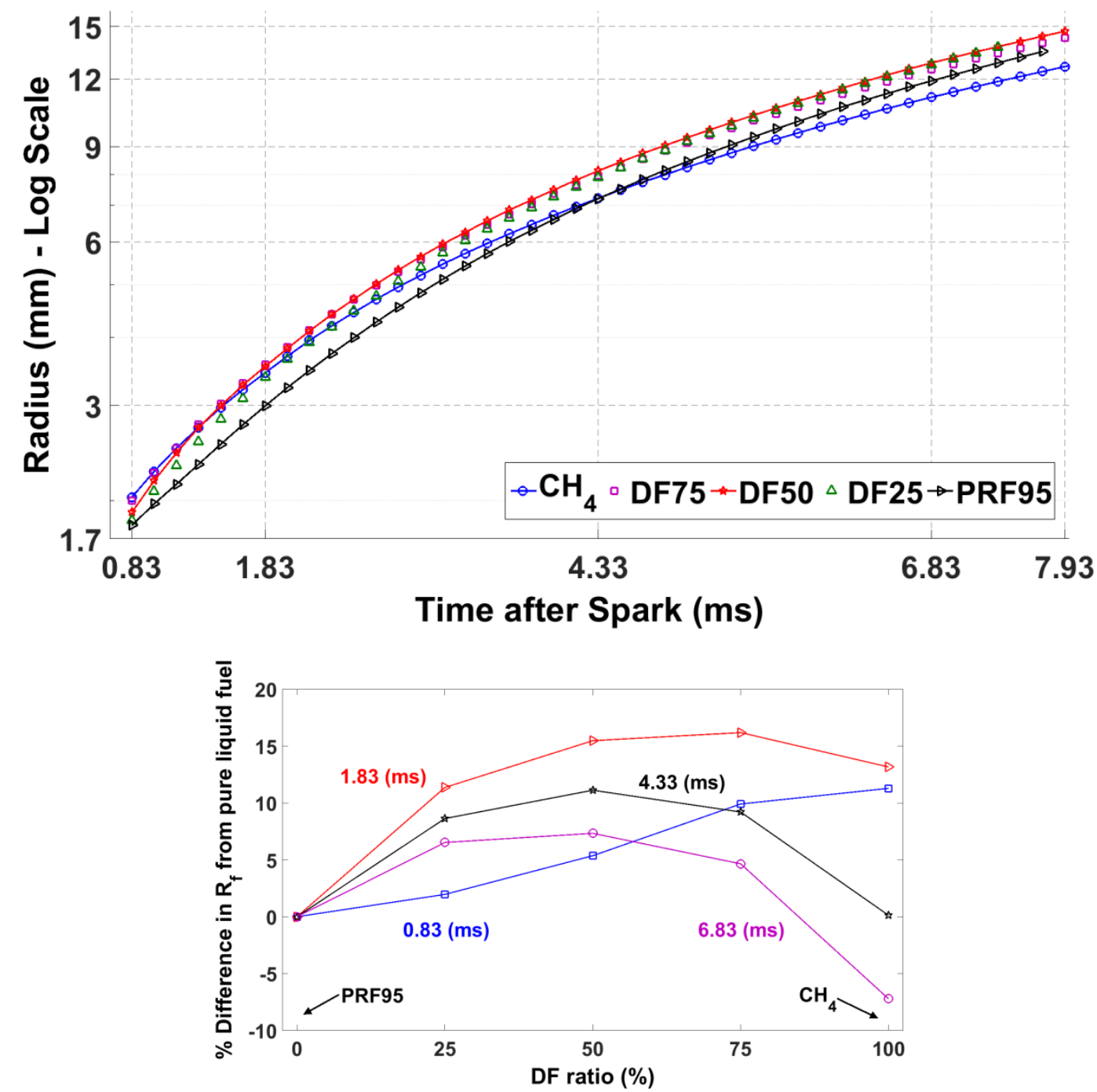

273 Figure 6. Average flame evolution of all fuels at Pinitial = 5Bar (upper plot). Sensitivity of the flame's radius to the 274 DF ratio (lower plot)

275 At 0.83 ms after spark, it has been found that with the addition of methane to PRF95 in a dual fuel blend the

276 flame radius is increased. Moving to $1.83 \mathrm{~ms}$, DF75 is having the largest radius and PRF the smallest. The radius

277 of methane's flame is smaller than those of DF50 and DF75 whereas is marginally larger than that of DF25. From

2781.83 to $7.93 \mathrm{~ms}$, the flame evolution of the DF50 blend forms a medium between all of the test fuels and is the

279 first to reach the maximum allowed radius at a time of $7.93 \mathrm{~ms}$. The flame evolution of DF25 and PRF95 are

280 converging towards DF50 in contrast to DF75 and $\mathrm{CH} 4$ that are diverging.

281 The studies of Brequigny et al. $[17,18]$ present the flame evolution of methane and iso-octane flames in an SI

282 engine. Similar qualitative trends have been found in comparison to the base fuels of the current study. During

283 the initial stages of flame evolution, methane has been found to have a larger flame radius as compared to iso-

284 octane, and gradually as the flame develops, the flame radius of iso-octane to converge to the radius of methane. 
285 In the current study, similar overall trends in flame evolution could be observed at a pressure of 2.5 and 10 Bar.

286 It has to be noted that at a pressure of 10 Bar the flame radius at the early stages of combustion was

287 considerable higher as the dual fuel ratio was increased.

288 The flame evolution of the different fuels at a pressure of 5 bar is complemented with plots of burning velocity

289 versus time and versus radius presented in the subplot shown in Figure 7. To allow for the maximum amount of

290 data points to be presented especially in the initial period of the flame evolution, the burning velocity for each fuel

291 has been calculated using successive radius differences, and smoothed with a second order polynomial filter only

292 for the presentation purposes of Figure 7. The burning velocity of all fuels is initially increasing attributed to the

293 effect of a decreasing stretch for a mixture of a positive Markstein length. PRF95 is found to give the largest

294 increase in speed whereas methane the lowest. From 0.83 to $1.83 \mathrm{~ms}$ after spark corresponding to a radius of 3

$295 \mathrm{~mm}$, methane is found to be faster than PRF95 although it was slower than all DFs. Initially, the fastest burning

296 fuel is DF50 whereas at about $2 \mathrm{~ms}$ after spark corresponding to $5 \mathrm{~mm}$ in radius, the burning velocity of DF25

297 reaches and eventually crosses that of DF50. From a radius of $8 \mathrm{~mm}$ onwards, PRF95 and DF50 have

298 comparable burning velocities whereas the velocity of DF75 is lower.

299 As already discussed, methane has the largest flame radius at $0.83 \mathrm{~ms}$ after spark. It seems that methane

300 exhibits the fastest burning velocity only for radii below $2 \mathrm{~mm}$ where flames have not been analysed, as they

301 could not be clearly observed and therefore precisely tracked by the image processing code.

302

303

304

305

306

307

308 

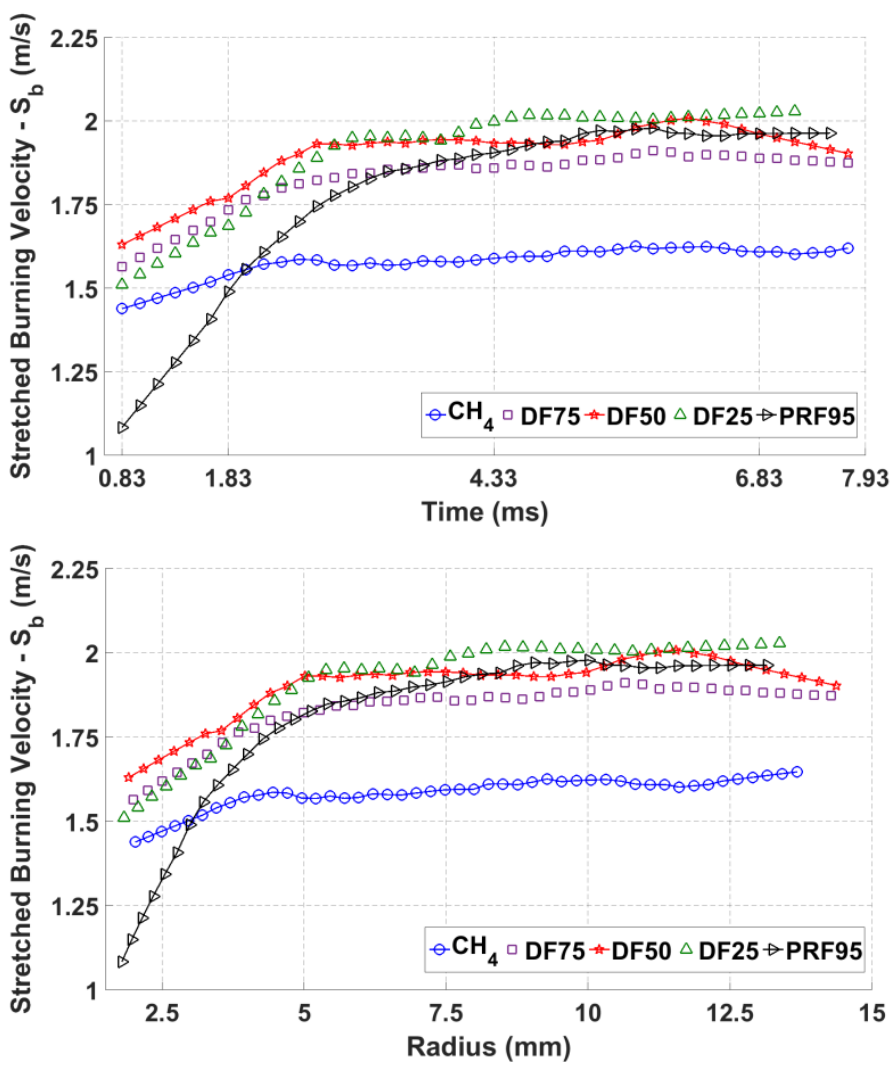

310 Figure 7. Temporal flame evolution speed (upper plot) and flame evolution speed relative to flame radius (lower 311 plot). Pinitial $=5$ bar.

312 The experimental study of Aleifraris et al. [19] reported the stretched burning velocity versus radius as acquired in

313 an SI engine during the early stages of combustion for stoichiometric methane, gasoline and iso-octane air

314 mixtures. The mass fraction burned versus time is also presented for the mentioned fuels for the whole

315 combustion process. It has been reported that up to a radius of $15 \mathrm{~mm}$ the burning velocity of methane is higher

316 than the velocity of gasoline and to a larger extend that of iso-octane. However, from a flame radius of about 10

$317 \mathrm{~mm}$ and onwards the burning velocity of gasoline and iso-octane gradually converges to that of methane and

318 eventually becomes faster as can be concluded from the available plot of mass fraction burned versus time. As it

319 was acknowledge in the study [19], the stretch rate experienced by the flames in the engine environment is

320 considerably higher than in constant volume laminar combustion experiments. Thus, the flame stretch sensitivity

321 is expected to have a greater influence on the burning velocity.

322 With the addition of methane to PRF95 is evident that flame evolution is altered. As the dual fuel ratio increases,

323 the flame is expanding faster at the early stages of combustion in contrast to the later stages of combustion

324 whereas the flame is expanding slower. Similar phenomena with regards to the base fuels of the current study

325 are also observed in real combustion applications [17-19]. In the present study, the evaluation of laminar flame

326 velocity and Markstein length will enhance the understanding behind the mechanism of flame evolution. For the 
327 three different test pressures, the effects of methane addition to PRF95 on both fundamental combustion

328 parameters will be quantified and discussed.

331 At the early stages of flame evolution, the ignition energy can affect the measured value of burning velocity. As suggested by Bradley et al. [6], the sharp fall in burning velocity $\left(S_{b}\right)$ with the stretch rate indicates that in this regime a fully developed flame is not yet established. Presented in Figure 8 is a selection of experimental data showing the variation of burning velocity with flame stretch rate for different fuels at a pressure of 5 Bar, as well as a single fuel (DF50) at all tested pressures. It has to be clarified that for all test conditions due to the differentiation method and the fact that the image processing code is initially applied at the $4^{\text {th }}$ frame after the initiation of spark, the first point of $S_{b}$ in Figure 8 corresponds to the burning velocity at the $9^{\text {th }}$ frame after spark.

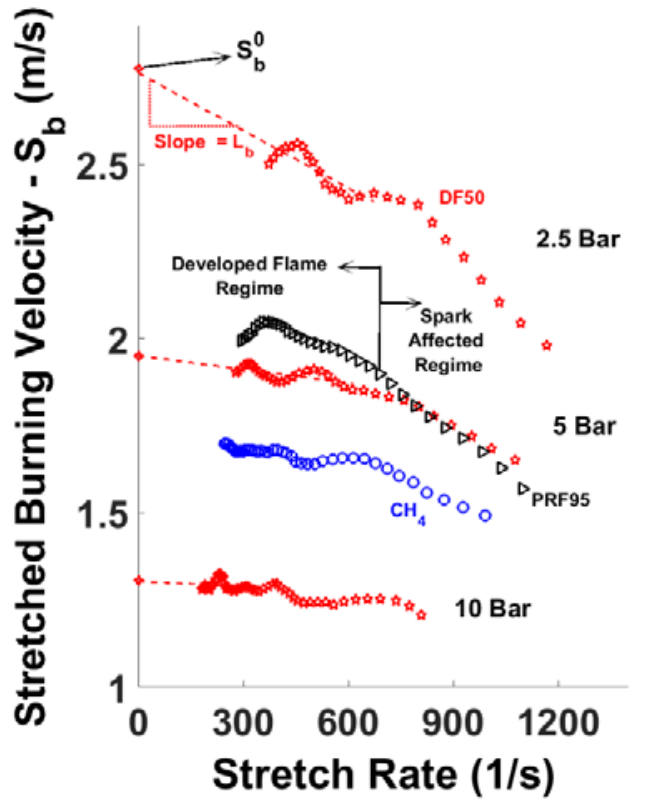

Figure 8. Stretched burning velocity versus stretch rate for three selected fuel-air mixtures.

340 Considering the plot of stretch burning velocity versus stretch rate, two distinct regimes can be identified; the

341 spark affected regime and the developed flame regime. As can be found in literature $[5,6,11]$ different researches 342 suggest that the ignition energy effect diminishes at flame radii between $5-10 \mathrm{~mm}$. In the present study, the 343 radius that corresponds to the upper boundary of the spark affected regime was found to be depended on the

344 test pressure as well as fuel. When the pressure is increased the radius is decreased. At each investigated 345 pressure, PRF95 resulted to have the largest radius, in contrast to methane that had the lowest. Thus, for each 346 investigated pressure, burning velocities associate with flame radii less than the radius at the upper boundary of 
347 the PRF95 flame have been excluded from further analysis. Data have been excluded for radii below $7 \mathrm{~mm}$ at 2.5

348 Bar, $6 \mathrm{~mm}$ at $5 \mathrm{Bar}$, and $5 \mathrm{~mm}$ at 10 Bar.

\subsection{2) Extrapolation procedure}

350 The unstretched flame velocity $\left(\mathrm{S}_{b}{ }^{0}\right)$ and the corresponding Markstein length can be determined using a linear

351 extrapolation through the largest possible range of radii where there is no spark influence, and where the curve of 352 stretch burning velocity versus stretch rate is reasonably linear [6]. The intersection of the extrapolated line back

353 to zero stretch corresponds to the value of the unstretched flame velocity. The gradient of the extrapolated line

354 corresponds to the value of the Markstein length

355 Historically, the choice of data range has been somewhat arbitrary. Different researchers made different choices 356 without giving quantitative justification [28]. In an effort to derive the values of the unstretched burning velocities

357 and Markstein lengths with a consistent approach, a sensitivity analysis has been performed through the selected

358 reasonably linear range of radii. The overall methodology is depicted in Figure 9, where the axes have been

359 magnified to point out the oscillatory trend of $S_{b}$ purely for presentation purposes. The observed oscillations of $S_{b}$

360 are induced by the unavoidable acoustic disturbances inside the vessel $[5,6]$. The lower boundary of the

361 sensitivity analysis is defined as the first point of the selected reasonably linear range. An extrapolated line is

362 fitted starting from the lower boundary and moving with increments of $0.5 \mathrm{~mm}$ in radius towards the upper

363 boundary. The upper boundary is defined as the point at which the value of Markstein length changes sign

364 compared to its initial sign at the lower boundary. Each extrapolated line within the range of sensitivity analysis is

365 giving a value of the unstretched burning velocity. The selected unstretched burning velocity is defined as the 366 average within one standard deviation of all the resulted values. The extrapolated line with its intersection giving 367 the closest value to that of the selected unstretched burning velocity (dashed red-blue) is used to define the value 368 of Markstein length. As is illustrated in Figure 8, the values of the Markstein length are defined as the slope of 369 the selected extrapolated lines. 


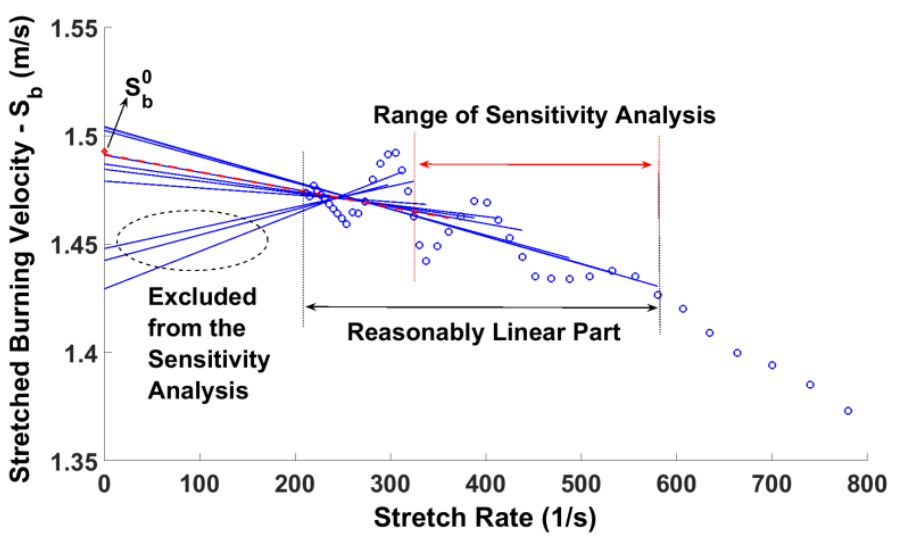

371 Figure 9. Definition of the sensitivity analysis applied at each test condition.

372 For each investigated pressure, five different fuels have been tested with a minimum of three repeats per fuel. A

373 sensitivity analysis has been performed to determine the value of $S_{b}{ }^{0}$ at each investigated repeat. At each

374 pressure, the average standard deviation of the unstretched burning velocities for all the tested repeats is

375 calculated and presented in Figure 10. Also for an immediate interpretation the coefficient of variation of $S_{b}{ }^{0}$ is

376 also shown at each pressure. It can be clearly observed that the uncertainty in the extrapolation procedure

377 indicated by the standard deviation of $\mathrm{S}_{\mathrm{b}}{ }^{0}$ appears to increase with the decrease of pressure. This trend is

378 attributed to the fact that the available data points within the developed flame regime and therefore the selected

379 linear range are reduced with a decrease in pressure due to a faster flame. Summarising the current analysis, it

380 is suggested that the reasonably linear range should be as large as possible to minimize the uncertainties from

381 the extrapolation procedure.

382

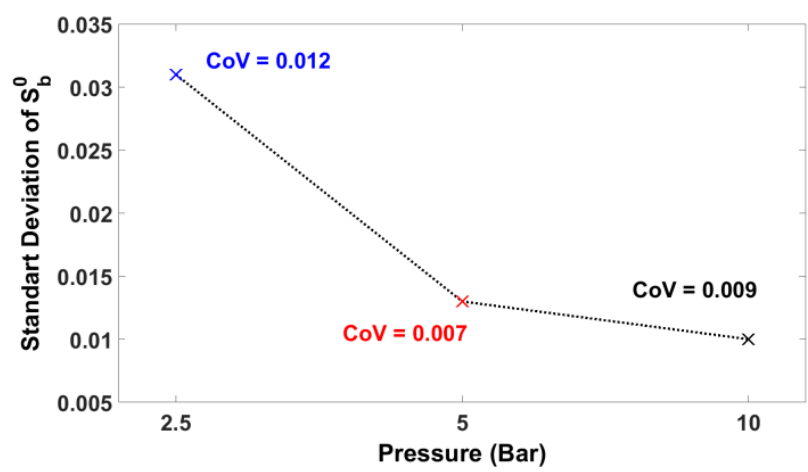


388 The influence of stretch rate on the burning velocity is characterised by the value of Markstein length ( $\left.L_{b}\right)$. For all 389 the presented conditions in Figure 8, as stretch rate increases $S_{b}$ is reduced. Therefore, stretch rate has an 390 adverse effect on the burning velocity which is indicative of a positive $L_{b}$. On the other hand, a negative $L_{b}$

391 indicates the increase of $S_{b}$ with stretch rate. Inspection of Figure 8 reveals that the difference in $S_{b}$ between 392 methane and PRF95 increases as the stretch rate is reduced. That's attributed to the different values of $L_{b}$ 393 between the two fuels. Up to a stretch rate of about $750 \mathrm{~s}^{-1}$, DF50 has a higher $\mathrm{S}_{\mathrm{b}}$ even compared to that of 394 PRF95.

395 The effects on $L_{b}$ both with respect to the DF ratio as well as pressure are depicted in Figure 11. At each 396 investigated point, error bars are evaluated based on the standard error of all the repeated tests. The uncertainty of the extrapolation procedure and the repeatability of the tests at each investigated point are contributing to the extent of the error bars. Available literature data are also presented in Figure 11 for the base fuels. For presentation purposes, the literature data are slightly shifted on the x-axis. It appears that there is no prior work reporting values of the $L_{b}$ for different ratios of methane addition to PRF95 at elevated pressures. At each test pressure, the data are correlated with a straight line fit (dotted lines) aiming to present the overall trend of $L_{b}$

402 relative to the DF ratio. The equations of the fitted lines are also presented.

403 Fuel effect on $L_{b}$ : Considering the uncertainty of the experimental results, it has been found that as the DF ratio

404 increases, $L_{b}$ is decreased following a fairly linear trend. The reduction of $L_{b}$ with the increase in DF ratio is

405 consistent at each tested pressure. However, at a pressure of 2.5 Bar the absolute reduction in $L_{b}$ is higher 406 (larger slope) than at 5 and 10 Bar where the reduction of $L_{b}$ with DF ratio is similar. With a 25\% increase in the 407 DF ratio, the value of $L_{b}$ is linearly reduced by $0.1,0.063,0.056 \mathrm{~mm}$ at pressure of $2.5,5$ and $10 \mathrm{Bar}$ 408 respectively. As percentages the above reductions correspond to $15 \%, 21 \%$, and $32 \%$, indicating that the burning 409 velocity becomes less sensitive to stretch as DF ratio increases. As pressure increases, the percentage 410 difference in stretch sensitivity with the increase of the DF ratio is larger. The responses have been calculated 411 based on the slopes of the fitted lines. 


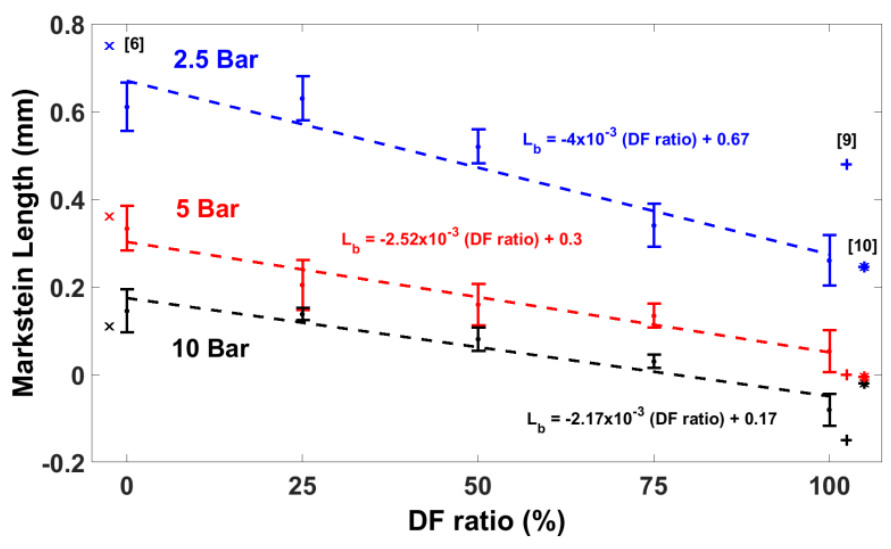

413 Figure 11. Burned gas Markstein lengths for all test conditions, and comparison with literature data reported by
414 Bradley et al. (x-markers) [6], Rozenchan et al. (stars) [10], and Gu et al. (crosses) [9].

413 Figure 11. Burned gas Markstein lengths for all test conditions, and comparison with liter.
414 Bradley et al. (x-markers) [6], Rozenchan et al. (stars) [10], and Gu et al. (crosses) [9].

415 Pressure effect on $L_{b}$ : The value of $L_{b}$ is not only affected by a change in fuel but is also affected by a change in

416 pressure. As pressure increases the value of $L_{b}$ is reduced for all fuels as can be clearly observed in Figure 11 .

417 The reduction of $L_{b}$ with pressure is following a non-linear trend. The absolute reduction of $L_{b}$ from 2.5 to 5 Bar is

418 larger than from 5 to 10 Bar for all fuels. For the same increase in pressure, the percentage reduction in $L_{b}$ is

419 larger with the increase of the DF ratio.

420 Available literature data are also presented in Figure 11. Bradley et al. [6] reported values of $L_{b}$ for an iso-octane-

421 air mixture at different pressures, temperatures and equivalence ratios. Appropriate values from that study are

422 illustrated with x-markers for a comparison to the values of PRF95 measured in the current study. For methane,

423 the reported values of $L_{b}$ from the experimental studies of Rozenchan et al. [10] (stars), and Gu et al. [9]

424 (crosses), are presented. Considering the reported discrepancies of the measured Markstein lengths by different

425 researchers [29] that can even be larger than 300\%, it can be concluded that the reported values of $L_{b}$ from the

426 current experimental work are in satisfactory quantitative and qualitative agreement with the selected values from 427 literature.

\section{4) Unstretched Burning Velocity $-S_{b}{ }^{0}$}

With the evaluation of $L_{b}$, the values of the unstretched burning velocity $\left(S_{b}{ }^{0}\right)$ of all fuels can now be presented. Values of $S_{b}{ }^{0}$ are presented in Figure 12. At each investigated pressure, derived values of $S_{b}{ }^{0}$ for all tested fuels are correlated with a straight line fit as shown by the dotted lines. The equations of the fitted lines are also presented. At a pressure of 10 Bar the value of $S_{b}{ }^{0}$ for the DF75 blend is considerably higher compared to the

433 rest of the fuels. As discussed in section 3.1.1, DF75 is thought to be affected by phenomena of flame instability 434 at 10 Bar. Therefore the $S_{b}{ }^{0}$ of DF75 is not taken into consideration for the linear fit correlation at a pressure of 10 435 Bar. 
436 Fuel effects on $S_{b}{ }^{0}$ : At a pressure of 2.5 and 5 Bar, the values of $S_{b}{ }^{0}$ are converging for all dual fuel ratios with a

437 distinct difference from the values of methane. This behaviour is not evident at a pressure of 10 Bar. As an

438 overall trend, it appears that as DF ratio increases, the value of $S_{b}{ }^{0}$ is decreased. The response is the same for

439 all the investigated pressures with the exception of DF75 blend at a pressure of 10 Bar. Following the slope of the

440 fitted lines, a $25 \%$ increase in the DF ratio, will decrease the value of $\mathrm{S}_{b}{ }^{0}$ by $0.12,0.11,0.1 \mathrm{~m} / \mathrm{s}$ at pressure of

$4412.5,5$ and 10 Bar respectively. As percentages these differences correspond to $4 \%$ at 2.5 Bar, $5 \%$ at 5 Bar, and

$4426.5 \%$ at 10 Bar.

443 Pressure effects on $S_{b}{ }^{0}$ : As pressure increases the value of $S_{b}{ }^{0}$ is decreased for all test fuels. For an increase in 444 pressure between 2.5 and 5Bar, the absolute reduction in $\mathrm{S}_{\mathrm{b}}{ }^{0}$ is smaller as DF ratio is increased. At a pressure 445 of 5 and 10 Bar the slope of the fitted lines appears to be comparable. Therefore, for an increase in pressure 446 from 5 to 10 Bar, the absolute difference in $S_{b}{ }^{0}$ is similar for all fuels apart from DF75. On average (evaluated 447 based on the difference of PRF95 and methane), the absolute reduction in $\mathrm{S}_{\mathrm{b}}{ }^{0}$ from 2.5 to 5 Bar corresponds to $4480.8 \mathrm{~m} / \mathrm{s}$ and $0.56 \mathrm{~m} / \mathrm{s}$ from 5 to 10 Bar. The adverse effect of pressure on $\mathrm{S}_{\mathrm{b}}{ }^{0}$ is reduced as pressure is increased 449 for all fuels.

450

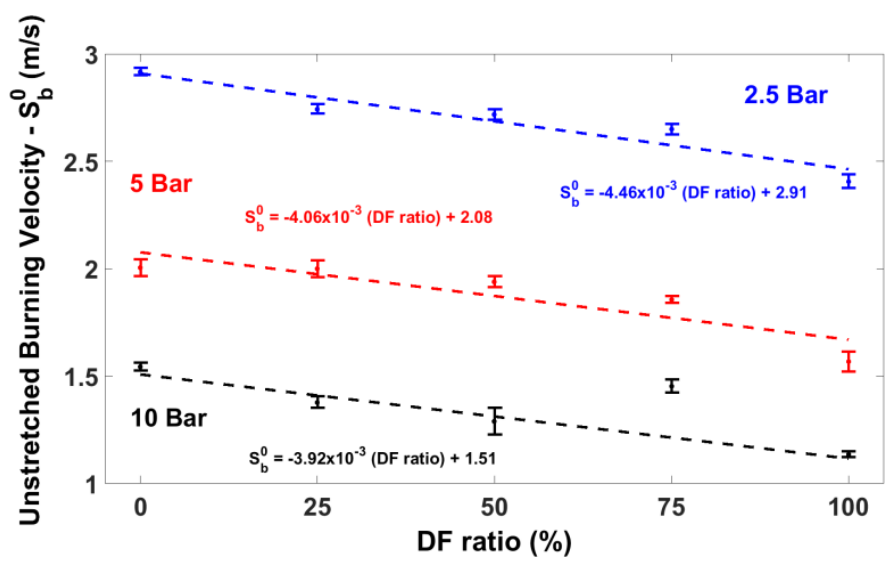

\section{5) Fundamental Laminar Flame Velocity $-S_{u}{ }^{0}$}

454 The fundamental laminar flame velocity $\left(S_{u}{ }^{0}\right)$ can be derived by dividing the already reported values of $S_{b}{ }^{0}$ with 455 the appropriate expansion factors. The required expansion factors are depended both on the fuel as well as on 456 the test pressure. At each investigated condition the computed expansion factors are presented in Figure13. It 457 can be observed that with the increase of the DF ratio, the expansion factor is reduced in a fairly linear manner at 458 all three test pressures. This behaviour is mainly attributed to the different molecular weight of each fuel, with 

pressure is concerned, the value of the expansion factors at 2.5 Bar is on average $2 \%$ lower as compared to the values at 10 Bar. The difference is attributed to the effect of pressure on the equilibrium state of the burned gas.

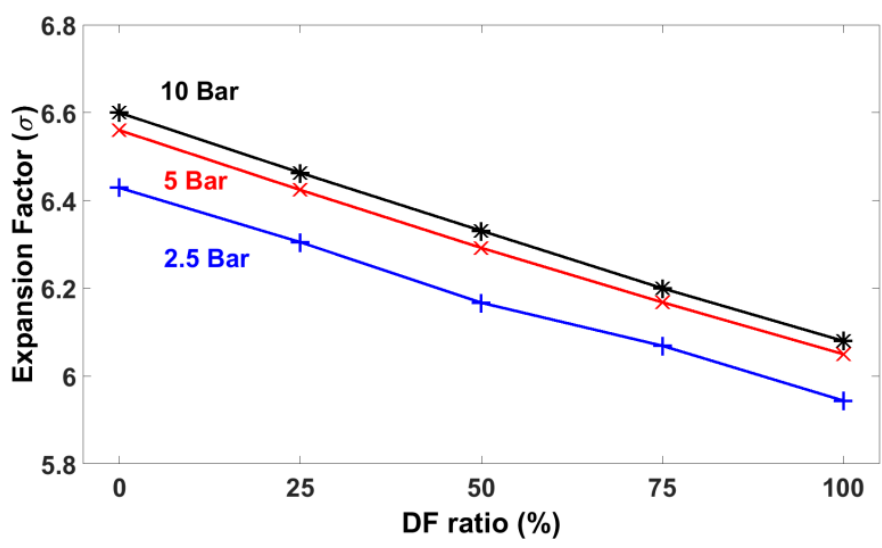

464 The resulted values of $\mathrm{S}_{\mathrm{u}}{ }^{0}$ with their corresponding error bars are presented in Figure14 for all the investigated conditions. At each investigated pressure, the resulted values of $\mathrm{S}_{\mathrm{u}}{ }^{0}$ are well correlated with a straight line fit (dotted lines) similar to the data of $\mathrm{S}_{b}{ }^{0}$. The equations of the fitted lines are also presented in the figure. The considerably higher value of DF75 at 10 Bar is not taken into consideration for the fitting process. Available literature data are also included in the plot. For presentation purposes, the literature data are slightly shifted on the x-axis. For methane, data are taken from the work of Gu et al. (stars) [9]. For PRF95 data are taken from the work of Bradley et al. (x-markers) [6], Jurzembeck et al. (cross) [5], and Beeckmann et al. (triangle) [8]. It appears

471 that there is no prior literature study reporting values of laminar flame velocities of methane-PRF95 dual fuel 472 blends at elevated pressures.

473 Fuel effects on $S_{u}{ }^{0}$ : Considering the slope of the fitted lines as presented in Figure 14, it can be concluded that 474 as the pressure increases, the percentage reduction in $\mathrm{S}_{\mathrm{u}}{ }^{0}$ is larger with the increase of the DF ratio. With a $25 \%$ 475 increase in the DF ratio, the value of $\mathrm{S}_{\mathrm{u}}{ }^{0}$ is reduced by $2 \%, 3 \%$ and $5 \%$ at pressure of $2.5,5$ and 10 Bar respectively. These percentage differences are on average $2 \%$ lower as compared to those derived for $\mathrm{S}_{\mathrm{b}}{ }^{0}$, attributed to the unequal expansion factors of each fuel.

478 Pressure effects on $S_{u}{ }^{0}$ : As is clearly presented in Figure 14, with the increase of pressure, $\mathrm{S}_{\mathrm{u}}{ }^{0}$ is reduced .

479 However, the reduction of $\mathrm{S}_{\mathrm{u}}{ }^{0}$ is larger for an increase in pressure between 2.5 and 5Bar in comparison to an increase in pressure from 5 to 10 Bar. The adverse effect of pressure on $S_{u}{ }^{0}$ is reduced as pressure is increased

481 for all fuels. For the methane flame, the percentage reduction in $\mathrm{S}_{\mathrm{u}}{ }^{0}$ is $2 \%$ and $5 \%$ higher than that of PRF95, 
$483 \mathrm{~S}_{\mathrm{u}}{ }^{0}$ of methane is more sensitive in pressure than that of PRF95. This response is consisted with literature [9].

484 For all DFs, the percentage reduction with an increase in pressure is between the values corresponding to the 485 pure liquid fuel (PRF95) and the gaseous fuel $\left(\mathrm{CH}_{4}\right)$.

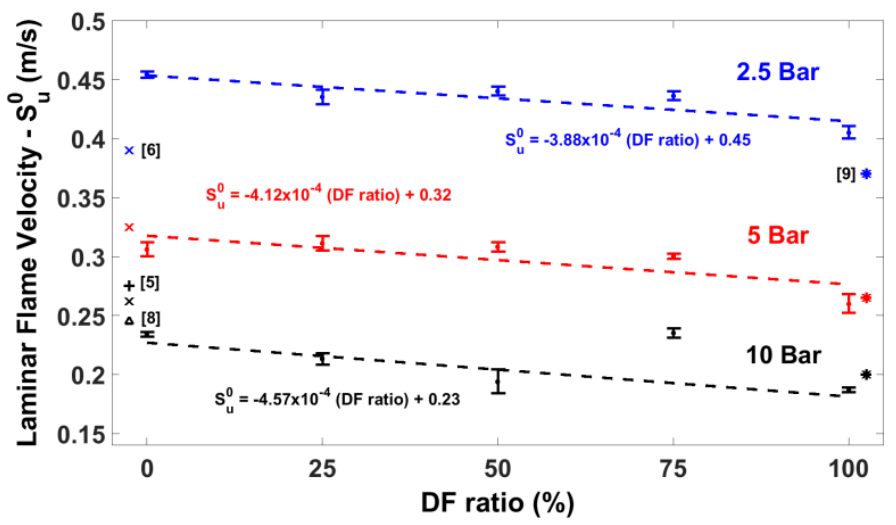

Figure 14 Laminar Flame Velocities at all test conditions, and comparison with literature data reported by Bradley 488 et al. (x-markers) [6], Jurzembeck et al. (cross) [5], Beeckmann et al. (triangle) [8], and Gu et al. (stars) [9].

489 As illustrated in Figure 14, at a pressure of 2.5 Bar the experimental values of $\mathrm{S}_{\mathrm{u}}{ }^{0}$ obtained in this work are on average $11 \%$ higher compared to those reported in literature. This trend does not show on the other two investigated pressures. There is a maximum deviation of $15 \%$ between the values of $\mathrm{S}_{\mathrm{u}}{ }^{0}$ obtained in this work as compared to the ones reported in literature. The maximum deviation corresponds to the value of PRF95 at a pressure of 10 Bar.

With the evaluation of both fundamental combustion parameters $L_{b}$ and $S_{u}{ }^{0}$, the mechanism behind the flame evolution as discussed in section 3.1.2 can now be explained. At a pressure of 5 Bar, with a $25 \%$ increase in the DF ratio, the values of $S_{u}{ }^{0}$ and $L_{b}$ are reduced by $3 \%$ and $21 \%$ respectively. As already discussed, at the early stages of combustion the flame radius is increased with DF ratio. It is clear that the mechanism behind this phenomenon is attributed to the decrease of $L_{b}$ as the dual fuel ratio is increased. As the flame develops and flame radius is increasing, stretch rate is reduced. This implies that the effect of $L_{b}$ on the flame velocity is decaying. Therefore $S_{u}{ }^{0}$ will start to dominate the flame evolution. As a result, an increase in the DF ratio will

501 slow down the flame evolution. Indeed, the flame evolution of PRF95 becomes gradually faster than that of methane as the combustion process progress.

503 The effects of methane addition to PRF95 on the fundamental combustion parameters, laminar flame velocity

$506\left(S_{u}{ }^{0}\right)$ and Markstein length $\left(L_{b}\right)$, were experimentally investigated at a stoichiometric air to fuel ratio, different 

to measure burning velocitys, from which the corresponding $\mathrm{L}_{\mathrm{b}}$ and $\mathrm{S}_{\mathrm{u}}{ }^{0}$ were derived. Where applicable, values obtained from this work were compared with reported data in literature. It appears that there is no prior work reporting values of either $L_{b}$ or $S_{u}{ }^{0}$ for different DF ratios at elevated pressures. by $15 \%, 21 \%, 32 \%$ at a pressure of $2.5,5$ and 10 Bar respectively. As pressure increases, $L_{b}$ is reduced for all fuels. The absolute reduction of $L_{b}$ from 2.5 to 5 Bar is larger than from 5 to 10 Bar. For the same increase in pressure, the percentage reduction in $L_{b}$ is larger with the increase of the DF ratio. A satisfactory qualitative and quantitate agreement with the appropriate values from literature was obtained.

517 As far as $\mathrm{S}_{\mathrm{u}}{ }^{0}$ is concerned, it has been found that with a $25 \%$ increase in the DF ratio, the value of $\mathrm{S}_{\mathrm{u}}{ }^{0}$ is reduced

518 by $2 \%, 3 \%$ and $5 \%$ at pressure of $2.5,5$ and 10 Bar respectively. As pressure increases, $\mathrm{S}_{\mathrm{u}}{ }^{0}$ is reduced for all

519 fuels. For the same increase in pressure, the percentage reduction in $\mathrm{S}_{\mathrm{u}}{ }^{0}$ is larger with the increase of the DF

520 ratio. There is a maximum deviation of $15 \%$ between the values of $\mathrm{S}_{\mathrm{u}}{ }^{0}$ obtained in this work and those reported in

521 literature.

522 At the early stages of combustion, the flame evolution is found to be faster with the increase in the DF ratio, and

523 gradually as the flame develops it becomes slower. At the early stages of combustion $L_{b}$ has a dominant effect on

524 the flame evolution. As the flame develops, stretch rate is reduced, and $\mathrm{S}_{\mathrm{u}}{ }^{0}$ becomes the governed parameter for 525 the flame evolution.

\section{5) References}

1. Di lorio S, Sementa P, Vaglieco B. Experimental Investigation of a Methane-Gasoline Dual-Fuel Combustion in a Small Displacement Optical Engine. SAE Paper 2013-24-0046; 2013.

2. Di lorio $S$, Sementa $P$, Vaglieco $B$, Catapano F. An experimental investigation on combustion and engine performance and emissions of a methane-gasoline dual-fuel optical engine. SAE Paper 2014-01-1329; 2014.

3. Burke MP, Chen Z, Ju Y, Dryer FL. Effect of cylindrical confinement on the determination of laminar flame speeds using outwardly propagating flames. Combust Flame 2009; 156:771-79.

4. Tian G, Daniel R, Li H, Xu H, Shuai S, Richards P. Laminar Burning Velocities of 2,5-Dimethylfuran Compared with Ethanol and Gasoline. Energy Fuels 2010; 24:3898-3905.

5. Jerzembeck S, Peters N, Desjardins PP, Pitsch H. Laminar burning velocities at high pressure for primary reference fuels and gasoline: Experimental and numerical investigation. Combust Flame 2009; 156: 292301.

6. Bradley D, Hicks RA, Lawes M, Sheppard CGW, Wolley E. The Measurement of Laminar Burning Velocities and Markstein Numbers for Iso-octane-Air and Iso-octane-n-Heptane-Air Mixtures at Elevated Temperatures and Pressures in an Explosion Bomb. Combust Flame 1998; 115:126-44.

7. Mannaa O, Mansour MS, Roberts WL, Chung SH. Laminar burning velocities at elevated pressures for gasoline and gasoline surrogates associated with RON. Combust Flame 2015; 162: 2311-21.

8. Beeckmann J, Rohl O, Peters N. Numerical and Experimental Investigation of Laminar Burning Velocities of iso-Octane, Ethanol and n-Butanol. SAE Paper 2009-01-2784; 2009.

9. Gu XJ, Lawes JM, Wooley R. Laminar burning velocity and Markstein lengths of methane-air mixtures. Combust Flame 2000; 121: 41-58. 
10. Rozenchan G, Zhu DL, Law CK, Tse SD. Outward propagation, burning velocities, and chemical effects of methane flames up to 60 atm. Proc Combust Inst 2002; 29:1461-69.

11. Hassan MI, Aung KT, Faeth GM. Measured and predicted properties of laminar premixed methane/air flames at various pressures. Combust Flame 1998; 115: 539-50.

12. Brequigny P, Halter F., Rousselle CM, Moreau B, Dubois T. Thermodiffusive Effect on the Flame Development in Lean Burn Spark Ignition Engine. SAE Paper 2014-01-2630; 2014.

13. Petrakides S, Butcher D, Chen R, Gao D, Wei H. Experimental Study on the Burning Rate of Methane and PRF95 Dual Fuels, SAE Paper 2016-01-0804; 2016.

14. Bechtold JK, Matalon M, The dependence of the Markstein length on stoichiometry. Combust Flame 20011; 27:1906-13.

15. Muller UC, Bollig M, Peters N. Approximations for burning velocities and Markstein numbers for lean hydrocarbon and methanol flames. Combust Flame 1997; 108: 349-56.

16. Law CK, Sung CJ. Structure, aerodynamics, and geometry of premixed flamelets. Progress Energy Combust Sci 2000; 26:459-505.

17. Brequigny P., Halter F., Rousselle CM, Dubois T, Fuel performances in Spark-Ignition (SI) engines: Impact of flame stretch. Combust Flame 2016; 000:1-15.

18. Brequigny P., Rousselle CM, Halter F, Moreau B, Dubois T, Impact of Fuel Properties and Flame Stretch on the Turbulent Flame Speed in Spark-Ignition Engines. SAE Paper 2013-24-0054; 2013.

19. Aleiferis PG, Pereira JS, Richardson D. Characterisation of flame development with ethanol, butanol, isooctane, gasoline and methane in a direct-injection spark-ignition engine. Fuel 2013; 109:256-78.

20. Strehlow RA, Savage LD. The Concept of Flame Stretch. Combust Flame 1978; 31:209-11.

21. Law CK. Combustion Physics. Cambridge, New York 2006, p 405

22. Markstein GH. Non-Steady Flame Propagation. Pergamon, New York 1964, p22

23. Kelley AP, Law CK. Nonlinear effects in the extraction of laminar flame speeds from expanding spherical flames. Combust Flame 2009; 156:1844-51.

24. Halter F, Tahtouch T, Rousselle CM. Nonlinear effects of stretch on the flame front propagation. Combust Flame 2010; 157:1825-32.

25. Goodwin D, Malaya N, Moffat H, Speth R. Cantera: An object-oriented software toolkit for chemical kinetics, thermodynamics, and transport processes, Version 2.2. https://code.google.com/p/cantera/ ; [accessed 15.10.15]

26. Bradley D, Gaskell PH, Gu XJ. Burning velocities, markstein lengths, and flame quenching for spherical methane-air flames: A computational study. Combust Flame 1996; 104:176-98.

27. Qiao L, Kim CH, Faeth GM. Suppression effects of diluents on laminar premixed hydrogen/oxygen/nitrogen flames. Combust Flame 2005; 143:79-96.

28. Chen Z, Burke MP, Ju Y. Effects of compression and stretch on the determination of laminar flame speeds using propagating spherical flames. Combust Theory and Modelling 2009; 13:2:343-64.

29. Chen Z. Effects of radiation and compression on propagating spherical flames of methane/air mixtures near the lean flammability limit. Combust Flame 2010; 157:2267-76. 